\title{
SISTEM PENDUKUNG KEPUTUSAN DALAM PEMILIHAN HOTEL DI TANGERANG MENGGUNAKAN METODE AHP DAN TOPSIS
}

\author{
${ }^{1}$ Herry Sukma, ${ }^{1}$ Fenina Twince Tobing, ${ }^{2}$ Rena Nainggolan ${ }^{\bowtie}$ \\ ${ }^{1}$ Program Studi Teknik Informatika, Universitas Multimedia Nusantara, Tangerang, Indonesia \\ ${ }^{2}$ Program Studi Komputerisasi Akuntansi, Universitas Methodist Indonesia, Medan, Indonesia \\ Email: renanain66olan@gmail.com
}

DOI: https://doi.org/10.46880/jmika.Vol5No1.pp67-72

\begin{abstract}
Banten Province has a city, namely Tangerang, to be precise in the northern part of Banten City. There are many tourist attractions that we can visit in the city of Tangerang, such as natural scenery, historical places, natural scenery, photo spots and culinary tours. With various tourist attractions in the city of Tangerang, it attracts tourists who want to travel to these places. With so many interested tourists visiting the city of Tangerang, the existing hotel is one of the destinations for tourists who are visited for a place to stay and rest. This has had an impact on the increasing number of hotels in the area, which has led to an increasing variety of choices for tourists. To make it easier for tourists to choose a hotel according to their needs, a decision support system is needed in choosing a hotel to use for a place to stay and rest. Tourists can choose hotels according to their desired needs by using a decision support system with various criteria. The decision support system applies the initial criteria weighting by using the AHP method and hotel alternative ranking using the TOPSIS method. The system has been tested and implemented by distributing questionnaires to 30 respondents using the USE Questionnaire and applying the Sala Likert Method to perform the questionnaire calculations, and the final result obtained in the calculation of the questionnaire is $84.51 \%$.
\end{abstract}

Keyword: TOPSIS, AHP, Decision Support System, Hotel, Tangerang.

\section{ABSTRAK}

Provinsi Banten memiliki salah satu kota yaitu Tangerang, tepatnya berada di bagian Utara Kota Banten. Kota Tangerang memiliki beberapa tempat wisata yang bisa dikunjungi, seperti pemandangan alam, tempat bersejarah, pemandangan alam, tempat berfoto dan wisata kuliner. Dengan berbagai tempat wisata yang ada di kota Tangerang menjadikan daya tarik wisatawan ingin melakukan perjalanan ke tempat tersebut. Dengan banyaknya peminat wisatawan yang berkunjung ke Kota Tangerang menjadikan Hotel yang ada menjadi salah satu tujuan wisatawan yang dikunjungi untuk tempat menginap dan beristirahat. Hal tersebut sagat berdampak terhadap meningkatnya jumlah hotel yang ada di kawasan tersebut, yang menyebabkan semakin banyaknya variasi pilihan bagi wisatawan. Untuk mempermudah wisatawan dalam menentukan pemilihan hotel sesuai dengan kebutuhan, maka diperlukan suatu sistem untuk memberikan sebuah keputusan dinamakan sistem pendukung keputusan yang dapat digunakan dalam memilih hotel untuk tempat menginap dan beristirahat. Wisatawan dapat memilih hotel sesuai dengan kebutuhan yang diinginkan dengan menggunakan sistem pendukung keputusan dengan berbagai kriteria. Sistem pendukung keputusan menerapakan pembobotan kriteria awal dengan menggukan metode AHP dan perangkingan alternatif hotel dengan mengggunakan metode TOPSIS. Kuesioner telah diberikan terhadap 30 orang responden dengan menggunakan USE Questionnaire dan menerapkan Metode Sala Likert untuk melakukan perhitungan kuesioner, dan hasil akhir yang diperoleh dalam perhitungan kuesioner adalah sebesar $84.51 \%$ dan Sistem telah diuji coba dan diimplementasikan.

Kata Kunci: TOPSIS, AHP, Sistem Pendukung Keputusan, Hotel, Tangerang.

\section{PENDAHULUAN}

Di bagian Utara Ibukota Banten terdapat satu kota yang menjadi salah satu tujuan wisatawan yaitu Kota Tangerang. Bebera tempat wisata yang menjadi tempat detinasi wisata adalah pemandangan alam, tempat bersejarah, pemandangan alam, lokasi berfoto dan wisata kuliner, dengan berbagai tempat wisata yang menarik mengakibatkan banyak wisatawan yang berkunjung ke kota tersebut, baik wisawan lokal maupun mancanegara.

Menurut Dinas Kebudayaan dan Pariwisatara Pemerintah Kota Tangerang di Situs Resmi pada tahun 
2019 tercatat hingga bulan Juli 2018, yang berkunjung mencapai 883.089 wisatawan. Jumlah ini terus bertambah setiap tahunnya, pada tahun 2014 sebanyak 398.679 wisatawan, pada tahun 2015 sebesar 482.903 wisatawan, pada tahun 2016 sebanyak 554.299 wisatawan, pada tahun 2017 mengalami peningkatan yang sangat signifikan yaitu 1.008.747. Dengan meningkatnya kunjungan wisatwan dari tahun ketahun menjadi salah satu pemicu meningkatnya jumlah hotel di Kota Tangerang. Hotel adalah salah satu prasarana untuk mendukung meningkatnya wisatawan yang berkunjung kesuatu tempat tujuan wisata, dimana hotel adalah tempat beristirahat maupun menginap. Dengan meningaktnya jumlah hotel menjadikan banyaknya variasi pilihan bagi wisatawan sesuai dengan kebutuhan masing-masing wisatawan. Dengan banyaknya variasi pilihan hotel yang tersedia menyebabkan wisatawan sulit memilih hotel sesuai kebutuhan hal ini disimpulkan dengan melihat hasil penyebaran kuesioner terhadap 51 responden sebanyak $58.8 \%$ sulit untuk menentukan hotel mana yang dipilih sebagai tempat untuk bersistirahat maupun menginap. Dengan permasalahan tersebut, dibutuhkan sebuah sistem pendukung keputusan yang bisa membantu wisatawan dalam menentukan hotel untuk tempat bersistirahat dan menginap sesuai dengan kebutuhan wisatawan. Menurut survey pada tahun 2017 Situs TripAdvisor telah membantu wisatawan untuk menjajaki lebih dari 859 juta komentar dan opini tentang 8.6 juta akomodasi, maskapai penerbangan, restoran, testimoni dan kapal persiar.

Untuk melihat perbandigan harga untuk maskapai penerbangan dan hotel Tripadvisor juga bisa digunakan. Beberapa platform wisata telah menggunakan TripAdvisor sebagai ladasan ulasan resmi, Tiket.com, seperti Traveloka, dan Pegipegi. Tripadvisor digunakan sebagai landasan untuk mendapatkan data ulasan hotel dan berbagai fasilitas lainnya.

Kombinasi Analytic Herarchy Process (AHP) dan Technique for Other Reference by Similarity to Ideal Solution (TOPSIS) adalah metode yang terapkan dalam pemgambilan keputusan menurut (Andriyani \& Hafiz, 2018) dengan judul penelitian "Perbandingan Metode AHP dan TOPSIS Dalam Penentuan Siswa Berprestasi" menyimpulkan jika pembobotan kriteria menggunakan AHP sangat efektif sedangkans TOPSIS tidak sesuai dalam penentuan bobot kriteria, ini disebabkan tingginya angka subjektivitas yang mengakibatkan ketikdakkonsistenan hasil yang ddidapatkan. Dalam penelitian TOPSIS pada penelitian (Kaesmetan \& Nawa, 2017) diterapakan sebagai penentuan rangking dan penentuan bobot alternatif dan penelitian sebelumnya (Dwijayadi, Wirawan, \& Divayana, 2018) yang berjudul Pengembangan Sistem Pendukung Keputusan Penentuan Hotel Di Kecamatan Buleleng Dengan Metode Analytic Hierarchy Process (AHP) Dan Technique for Others Reference By Similarity To Ideal Solution (TOPSIS) ada 3 kriteria yang diterapkan, yaitu fasilitas, kelas dan biaya sewa kamar hotel. Dalam pemilihan hotel disimpulkan hotel yang tersedia di tiket.com sesuai dengan kebutuhan pengunjung dan kriteria yang diinginkan dengan menerapkan Metode SAW pada Sistem Pendukung Keputusan dan hal ini dapat dilakukan secara realtime. Dengan melihat latar belakang penelitian terdahulu, peneliti tertarik untuk membuat sebuah Sistem Pendukung Keputusan dengan tujuan suapaya antusiasn dari wisatawan lokal maupun mancanegara semakin tertarik dan atusias untuk berkunjun ke Kota Tangerang dimana salah satu destinasi wisawatan adalah hotel sebagai tempat untuk bersitirahat dan menginap.

Para wisatawan dibantu dalam penentuan keputusan pemilihan hotel di Kota Tangerang. Dengan menggunakan Metode yang digunakan yaitu Analytic Hierarchy Process (AHP) dan Technique for Other Reference by Similarity to Ideal Solution (TOPSIS) yang diterapkan pada Sistem Pendukung Keputusan

\section{TINJAUAN PUSTAKA}

\section{Sistem Pendukung Keputusan}

Sistem dimana pendukung seseorang manajer atau sekelompok kecil manajer yang bekerja sebagai tim pembuat keputusan atau problem solving team, untuk memberikan sebuah keputusan mengenai masalah semiterstruktur dengan cara memberikan sejumlah informasi yang spesifik juga mendefinisikan SPK sebagai model dari sekelompok prosedur untuk melakukan pengolahan data dengan tujuan membantu manajer dalam pembuatan keputusan spesifik disebut Sistem Pendukung Keputusan (SPK) (Wahyuni \& Anggoro, 2017)

Subsistem dari Komponen SPK terdiri berikut ini:

1. Subsistem Manajemen Data (Data Management Subsystem) disebut DBMS (Database Management System) data yang relevan dengan kondisi dan diolah oleh software.

2. Subsistem Manajemen Model (Model Management Subsystem), kemampuan untuk analisis paket software yang berisi statistic, management science, model-model finansial atau model kuantitatif, yang 
menyediakan kemampuan untuk software management.

3. Subsistem Manajemen Pengetahuan (Knowledge Management Subsystem), sebagai komponen yang berdiri sendiri (independent) mendukung subsistem yang lain dan merupakan subsistem (optional) yang berlaku

4. Subsistem Antarmuka Pengguna (User Interface Subsystem), yaitu (menyediakan user interface) dan berkomunikasi oleh user dan merupakan subsistem yang dapat dipakai memberi perintah

\section{Analytic Hierarchy Process (AHP)}

Menurut (Munthafa \& Mubarok, 2017) Analytic Hierarchy Process (AHP) oleh Thomas L. Saaty dalam bukunya Analytic Hierarchy Processm dikembangkan pertama kali pada Tahun 1980, adalah menggunakan perbandingan berpasangan (Pairwise Comparisons) dalam proses pengambilan keputusan untuk menjelaskan faktor bobot faktor evaluasi dalam kondisi multi faktor (Munthafa \& Mubarok, 2017). Sistem terkait menggunakan proses hirarki untuk menjabarkan kriteria dan elemen yang terdapat didalamnya, sehingga bisa dipahami dengan baik.

Menurut (Herman Firdaus, Abdillah, Renaldi, \& Jenderal Achmad Yani J1, 2016) terdapat langkahlangkah dan prosedur dalam metode penelitian AHP yang harus dilakukan sebagai berikut

1. Menentukan solusi yang diinginkan, lalu menyusun hierarkinya dengan terlebih dahulu mendefinisikan masalah
a. Membuat prioritas elemen
b. Menentukan perbandingan berpasangan.

2. Diisi menggunakan bilangan untuk merepresentasikan kepentingan relatif dari suatu elemen terhadap elemen yang lainnya yang disebut Matriks perbandingan berpasangan

3. Sintesis:

a. Setiap kolom pada matriks, setiap nilai-nilai ditambahkan

b. Untuk memperoleh normalisasi matriks nilai dari kolom dibagi dengan total yang bersangkutan

c. Untuk mendapatkan nilai rata-rata, tambahkan nilai-nilai dari setiap baris dan bagi dengan Jumlah elemen untuk

4. Menghitung konsistensi:
a. Prioritas relatif elemen kedua kalikan dengan setiap nilai pada kolom kedua dan seterusnya.
b. Setiap baris dilakukan penambahan

c. Hasil penambahan baris dibagi dengan elemen prioritas relatif yang bersangkutan.

d. Tambahkan hasil pembagian di atas dengan banyaknya elemen yang ada.

5. CI (Hitung Consistency Index)

$\mathrm{CI}=($ maks-n) $/ \mathrm{n} \ldots$ (2.1)

Hitung Rasio Konsistensi (Consistency Ratio)

$\mathrm{CR}=\mathrm{CI} / \mathrm{IR} \ldots$ (2.2)

Nilai Random indeks (IR) sesuai dengan ukuran matriks.

6. Hitung Consistency Ratio (Rasio Konsistensi)

$\mathrm{CR}=\mathrm{CI} / \mathrm{IR} \ldots$ (2.2)

Nilai random indeks (IR) dengan ukuran matriks.

7. Memeriksa konsistensi hierarki

Jika nilai $\mathrm{CR} \leq 0.1$ maka hasil perhitungan dinyatakan konsisten.

\section{Technique for Other Reference by Similarity to Ideal Solution (TOPSIS)}

Pertama kali diperkenalkan oleh Yoon dan Hwang (1981) Menyatakan bahwa TOPSIS adalah salah satu metode pengambilan keputusan multikriteria. Prinsip yang digunakan adalah bahwa alternatif yang terpilih harus mempunyai jarak terdekat dari solusi ideal dan terjauh dari solusi negatif berdasarkan sudut pandang geometris menggunakan jarak Eucledia untuk menentukan kedekatan relatif dari suatu alternatif dengan solusi optimal.

Secara umum, tahapan metode TOPSIS sebagai berikut (Doni, Amir, \& Juliawan, 2019):

1. Menentukan matriks keputusan yang ternormalisasi.

$$
x i j r i j=\ldots m i=12 i j
$$

2. Menghitung matriks keputusan yang ternormalisasi terbobot.

Tabel 1. Kriteria Hotel

3. Menghitung matriks solusi ideal negatif dan matriks solusi ideal positif.

$A^{+}=\left(y_{1}{ }^{+}, y_{2}{ }^{+}, \ldots, y_{\mathrm{n}}{ }^{+}\right)$
Kode Kriteria

$\mathrm{Kr} 1$

$\mathrm{Kr} 2$

$\mathrm{Kr} 3$

$\mathrm{Kr} 4$

$\mathrm{Kr} 5$

$$
V i j=W j \times R i j
$$

\section{Keterangan \\ Kriteria Harga \\ Kriteria Kelas \\ Kriteria Kebersihan \\ Kriteria Pelayanan \\ Kriteria Lokasi}


$A^{-}=\left(y_{1}^{+}, y_{2}^{+}, \ldots, y_{\mathrm{n}}^{-}\right)$

4. Hitunglah jarak antara nilai setiap alternatif dengan matriks solusi ideal positif dan matriks solusi ideal negatif.

$$
\begin{aligned}
& S+=\sqrt{ } \Sigma(V i j-V+) 2, j=1,2,, m \\
& j=1 \\
& S-=\sqrt{ } \Sigma(V i j-V-) 2, j=1,2,, m \\
& \quad j=1
\end{aligned}
$$

5. Menghitung nilai preferensi untuk setiap alternatif $R C=\frac{s i-}{s i+S i-}=1,2, \quad, \mathrm{~m}$ dan $0 \mathrm{RC}+\leq 1$

\section{Skala Likert}

Dalam kuesioner adalah suatu skala psikometrik yang umum diterapkan, dan survei adalah skala yang paling banyak diterapkan dalam riset berupa. Penentuan skala jawaban dilakukan dengan menggunakan angka 1 sampai 5, dimana 1 merupakan nilai sangat kurang hingga 5 merupakan nilai sangat baik dengan perhitungan sebagai berikut: (Maryuliana, Subroto, \& Haviana, 2016)

1. Perhitungan masing-masing pertanyaan kuesioner Dimana:

$$
\begin{aligned}
& \text { P1 }=\text { responden menjawab "Sangat Kurang" } \\
& \text { P2 }=\text { responden menjawab "Kurang" } \\
& \text { P3 }=\text { responden menjawab "Cukup" } \\
& \text { P4 }=\text { responden menjawab "Baik" } \\
& \text { P5 }=\text { responden menjawab "Sangat Baik" }
\end{aligned}
$$

2. Perhitungan interval dan perhitungan persen untuk memperoleh penilaian dengan Metode mencari Interval skor persen

$$
\text { Perhitungan }(\%)=\frac{\text { Total Skor }}{y} 100
$$

3. Dilakuakn setiap pertanyaan agar medapatkan hasil perhitungan skor

4. Perhitungan nilai rata-rata dari masing-masing skor perhitungan.

$$
\text { Mean }=\frac{V 1+V 2+\cdots+V n}{n} 100 \%
$$

Dimana

$\mathrm{V}=$ Variabel

$\mathrm{N}=$ Jumlah Variabel

Tabel 2. Ulasan Hotel si Tangerang

\begin{tabular}{|l|l|l|l|l|c|}
\hline & Harga & $\begin{array}{l}\text { Kl } \\
\mathrm{s}\end{array}$ & Keb & $\begin{array}{l}\text { Pel } \\
.\end{array}$ & Lokasi \\
\hline Novotel Hotel & Rp769.835 & 4 & 4 & 5 & $\begin{array}{l}15.9 \\
\text { KM }\end{array}$ \\
\hline Allium Hotel & Rp 489.050 & 4 & 5 & 5 & $\begin{array}{l}12.2 \\
\text { KM }\end{array}$ \\
\hline Narita Hotel & Rp 345.620 & 3 & 4 & 4 & $\begin{array}{l}13.1 \\
\text { KM }\end{array}$ \\
\hline FM7 Resort & Rp 562.686 & 4 & 5 & 4 & $5.5 \mathrm{KM}$ \\
\hline
\end{tabular}

\begin{tabular}{|l|l|l|l|l|c|}
\hline Golden Tulip & Rp 367.780 & 3 & 5 & 5 & $\begin{array}{c}14.4 \\
\text { KM }\end{array}$ \\
\hline De Green Inn & Rp 149.430 & 3 & 3 & 4 & $\begin{array}{c}12.3 \\
\text { KM }\end{array}$ \\
\hline $\begin{array}{l}\text { Bandara } \\
\text { International } \\
\text { Hotel }\end{array}$ & Rp 807.500 & 5 & 4 & 4 & $\begin{array}{c}2.4 \\
\mathrm{KM}\end{array}$ \\
\hline JHL Solitari & Rp 993.320 & 5 & 5 & 5 & $\begin{array}{c}34.2 \\
\mathrm{KM}\end{array}$ \\
\hline Amaris & $\mathrm{Rp} \mathrm{372.769}$ & 2 & 3 & 4 & $1.9 \mathrm{KM}$ \\
\hline Fame Hotel & $\mathrm{Rp} \mathrm{262.057}$ & 2 & 4 & 4 & $\begin{array}{c}34.5 \\
\mathrm{KM}\end{array}$ \\
\hline
\end{tabular}

Pada Tabel diatas merupakan acuan awal untuk menentukan nilai perbadingan berpasangan kriteria, guna mengetahui nilai consistenty ratio $(\mathrm{CR}) \leq 0.1$. Merupakan matriks perbandingan berpasangan antar kriteri hotel.

Tabel 3. Matriks Perbandingan Berpasangan Kriteria

\begin{tabular}{|l|l|l|l|l|l|}
\hline & Cr1 & Cr2 & Cr3 & Cr4 & Cr5 \\
\hline Cr1 & 1.0000 & 2.0000 & 4.0000 & 3.0000 & 4.0000 \\
\hline Cr2 & 0.5000 & 1.0000 & 2.0000 & 4.0000 & 2.0000 \\
\hline Cr3 & 0.2500 & 0.5000 & 1.0000 & 1.0000 & 5.0000 \\
\hline Cr4 & 0.3333 & 0.2500 & 1.0000 & 1.0000 & 1.0000 \\
\hline Cr5 & 0.2500 & 0.5000 & 0.2000 & 1.0000 & 1.0000 \\
\hline
\end{tabular}

Dilanjutkan dengan menjumlahkan nilai-nilai setiap kolom matriks dan membagi setiap nilai dari kolom dengan total keseluruhan kolom bersangkutan yang disebut dengan normalisasi matriks. Penjelasan lebih lanjut dapat dilihat sebagai berikut.

$\mathrm{Cr} 1=1.0000 / 2.3333=0.4286$

$\mathrm{Cr} 2=0.5000 / 2.3333=0.2143$

$\mathrm{Cr} 3=0.2500 / 2.3333=0.1071$

$\mathrm{Cr} 4=0.3333 / 2.3333=0.1429$

$\mathrm{Cr} 5=0.2500 / 2.3333=0.1071$

\section{Proses TOPSIS}

Setelah dilakukan proses metode AHP yang diperoleh hasil nilai eigen kriteria, maka proses dapat dilanjutkan dengan metode TOPSIS dengan membuat matriks keputusan ternormalisasi. Tahap awal yaitu dengan mendefinisikan nama setiap alternatif seperti pada tabel dibawah ini.

Tabel 4. Inisialisasi Nama Hotel

\begin{tabular}{|c|c|}
\hline $\begin{array}{l}\text { Kode } \\
\text { Alternatif }\end{array}$ & Nama Hotel \\
\hline A1 & Novotel Hotel \\
\hline A2 & Allium Hotel \\
\hline A3 & Narita Hotel \\
\hline A4 & FM7 Resort \\
\hline A5 & Golden Tulip \\
\hline A6 & De Green Inn \\
\hline A7 & Bandara International Hotel \\
\hline
\end{tabular}




\begin{tabular}{|c|c|}
\hline A8 & JHL Solitari \\
\hline A9 & Amaris \\
\hline A10 & Fame Hotel \\
\hline
\end{tabular}

Selain itu, untuk menentukan bobot setiap kriteria hoterl terhadap alternatif, dilakukan proses konversi dengan menggunakan keterntuan tabel dibawah ini.

Tabel 5. Ketentuan Bobot Kriteria Harga

\begin{tabular}{|c|c|c|}
\hline \multicolumn{3}{|c|}{ Kriteria Harga (Cr1) } \\
\hline Cr1 & Rentang Harga & Keterangan \\
\cline { 2 - 3 } & $<\operatorname{Rp~} 200.000$ & 1 \\
\hline \multirow{4}{*}{$\operatorname{Rp~} 200.000 \leq X<\operatorname{Rp} 400.000$} & 2 \\
\cline { 2 - 3 } & $\operatorname{Rp} 400.000 \leq X<\operatorname{Rp} 600.000$ & 3 \\
\hline $\operatorname{Rp} 600.000 \leq X<\operatorname{Rp} 800.000$ & 4 \\
\hline & $\geq \operatorname{Rp} 800.000$ & 5 \\
\hline
\end{tabular}

Tabel 6. Ketentuan Bobot Kriteria Kelas

\begin{tabular}{|c|c|c|}
\hline \multirow{2}{*}{ Kr2 } & Kriteria Kelas Hotel (Cr2) \\
\cline { 2 - 3 } & Kelas Hotel & Keterangan \\
\hline \multirow{4}{*}{ 1 Star Hotel } & 2 \\
\hline 2 Star Hotel & 3 \\
\hline 3 Star Hotel & 4 \\
\hline 4 Star Hotel & 5 \\
\hline
\end{tabular}

Tabel 7. Ketentuan Bobot Kriteria Kebersihan Kriteria Kebersihan(Cr3)

\begin{tabular}{|c|c|c|}
\hline Cr3 & Kebersihan & Keterangan \\
\cline { 2 - 3 } & 1 Star Hotel & 1 \\
\hline & 2 Star Hotel & 2 \\
\hline 3 Star Hotel & 3 \\
\hline & 4 Star Hotel & 4 \\
\hline & 5 Star Hotel & 5 \\
\hline
\end{tabular}

Tabel 8. Ketentuan Bobot Kriteria Pelayanan

\begin{tabular}{|c|c|c|}
\hline \multirow{2}{*}{ Cr4 } & Kriteria Pelayanan (Cr4) \\
\cline { 2 - 3 } & Pelayanan & Keterangan \\
\hline \multirow{4}{*}{ 1 Star Hotel } & 1 \\
\hline 2 Star Hotel & 2 \\
\hline 3 Star Hotel & 3 \\
\hline & 4 Star Hotel & 5 \\
\hline 5 Star Hotel & 5 \\
\hline
\end{tabular}

Tabel 9. Ketentuan Bobot Kriteria Lokasi

\begin{tabular}{|c|c|c|}
\hline \multicolumn{3}{|c|}{ Kriteria Lokasi (Cr5) } \\
\hline \multirow{3}{*}{ Cr5 } & Jarak dari Bandara & Keterangan \\
\cline { 2 - 3 } & $<5 \mathrm{KM}$ & 1 \\
\cline { 2 - 3 } & $5 \leq \mathrm{X}<10 \mathrm{KM}$ & 2 \\
\hline & $10 \leq \mathrm{X}<20 \mathrm{KM}$ & 3 \\
\hline
\end{tabular}

\begin{tabular}{|c|c|c|}
\hline $20 \leq X<30 \mathrm{KM}$ & 4 \\
\hline$\geq 30 \mathrm{KM}$ & 5 \\
\hline
\end{tabular}

\section{Evaluasi Sistem}

Tahap terakhir pada implementasi dan analissi adalah evaluasi dilakukan dengan menyebarkan kusieoner kepada 30 respondenPertanyaan yang diajukan kepada responden menggunakan metode USE Questionanire berjumlah 30 pertanyaan. Penerima kuesioner diminta untuk memberikan penilaian dan pernyataan, dimulai dari sangat tidak setuju hingga sangat setuju. Hasil kuesioner akan digunakan untuk mengevaluasi sikap pengguna. Faktor analisis juga mengikuti setiap penilian menyarankan bahwa pengguna mengevaluasi produk menggunakan tiga dimensi, yaitu Usefulnes, Satisfaction, dan Ease of Use(Lund, 2001)

Pada aspek usefulness, terdapat 8 pertanyaan yang diajukan kepada responden. Berikut tabel rekapitulasi kuesioner untuk aspek usefulness pada Tabel.

Tabel 11. Hasil Rekapitulasi Kuesioner Aspek Usefulness

\begin{tabular}{|c|c|c|c|c|c|}
\hline $\begin{array}{c}\text { Pertanyaan } \\
\text { Ke- }\end{array}$ & STS & TS & C & S & SS \\
\hline $\mathbf{1}$ & 0 & 0 & 2 & 17 & 11 \\
\hline $\mathbf{2}$ & 0 & 3 & 7 & 8 & 12 \\
\hline $\mathbf{3}$ & 0 & 1 & 1 & 15 & 13 \\
\hline $\mathbf{4}$ & 0 & 2 & 5 & 13 & 10 \\
\hline $\mathbf{5}$ & 0 & 0 & 2 & 20 & 8 \\
\hline $\mathbf{6}$ & 0 & 0 & 3 & 12 & 15 \\
\hline $\mathbf{7}$ & 0 & 0 & 4 & 16 & 10 \\
\hline $\mathbf{8}$ & 0 & 1 & 9 & 13 & 7 \\
\hline Total & 0 & 7 & 33 & 114 & 86 \\
\hline
\end{tabular}

Ease of Use

Pada aspek ease of use, terdapat 11 pertanyaan yang diajukan kepada responden. Berikut tabel rekapitulasi kuesioner untuk aspek ease of use yang dijabarkan pada tabel dibawah ini

Tabel 12. Hasil Rekapitulasi Kuesioner Aspek Ease of Use

\begin{tabular}{|c|c|c|c|c|c|}
\hline $\begin{array}{c}\text { Pertanyaan } \\
\text { Ke- }\end{array}$ & STS & TS & C & S & SS \\
\hline $\mathbf{1}$ & 0 & 0 & 1 & 12 & 17 \\
\hline $\mathbf{2}$ & 0 & 1 & 2 & 13 & 14 \\
\hline $\mathbf{3}$ & 0 & 0 & 3 & 13 & 14 \\
\hline $\mathbf{4}$ & 0 & 0 & 4 & 15 & 11 \\
\hline $\mathbf{5}$ & 0 & 1 & 2 & 13 & 14 \\
\hline
\end{tabular}




\begin{tabular}{|c|c|c|c|c|c|}
\hline $\mathbf{6}$ & 0 & 1 & 3 & 15 & 11 \\
\hline $\mathbf{7}$ & 0 & 2 & 5 & 12 & 11 \\
\hline $\mathbf{8}$ & 1 & 3 & 3 & 13 & 10 \\
\hline $\mathbf{9}$ & 0 & 1 & 1 & 13 & 15 \\
\hline $\mathbf{1 0}$ & 0 & 0 & 7 & 15 & 8 \\
\hline $\mathbf{1 1}$ & 0 & 0 & 1 & 18 & 11 \\
\hline Total & 1 & 9 & 32 & 152 & 136 \\
\hline
\end{tabular}

\section{Ease of Learning}

Pada aspek ease of learning terdapat 4 pertanyaan yang diajukan kepada responden.

Tabel 13. Hasil Rekapitulasi Kuesioner Aspek Ease of Learning

\begin{tabular}{|c|c|c|}
\hline Aspek & $\begin{array}{c}\text { Persentase } \\
\text { Perhitungan }\end{array}$ & Pernyataan \\
\hline Usefulnes & $83.25 \%$ & Sangat Baik \\
\hline Ease of Use & $85.03 \%$ & Sangat Baik \\
\hline $\begin{array}{c}\text { Ease of } \\
\text { Learning }\end{array}$ & $87.67 \%$ & Sangat Baik \\
\hline Satisfaction & $83.33 \%$ & Sangat Baik \\
\hline Keseluruhan & $84.51 \%$ & Sangat Baik \\
\hline
\end{tabular}

\section{KESIMPULAN}

Berdasarkan penelitian yang telah dilaksanakan, dengan menggunakan metode Technique fo Order Preference by Similarity to Ideal Solution (TOPSIS) dan Analytic Hierarchy Process (AHP) yang diterapkan pada sistem pendukung keputusan pemilihan hotel di Tangerang telah berhasil diimplementasikan. Sistem yang dibangun dapat memberikan rekomendasi alternatif hotel sesuai dengan lima kriteria yang telah ditentukan pengguna, yaitu, kelas, kebersihan, pelayanan, harga dan lokasi hotel.

Selain itu, telah dilaksanakan pengujian sistem dengan memebrikan kuesioner kepada 30 responden. Metode yang digunakan pada kuesioner adalah USE Questionnaire dengan perhitungan menggunakan Skala Likert. Diperoleh hasil persentase keseluruhan berdasarkan penilaian sistem sebesar $84.51 \%$, dengan hasil konversi menjadi nilai kualitatif memperoleh nilai sangat baik.

\section{DAFTAR PUSTAKA}

Andriyani, N., \& Hafiz, A. (2018). Perbandingan Metode AHP dan Topsis dalam Penentuan Siswa Berprestasi. Seminar Nasional Teknologi Dan Bisnis 2018, 362-371.

Doni, R., Amir, F., \& Juliawan, D. (2019). Sistem Pendukung Keputusan Kenaikan Jabatan

Menggunakan Metode Technique for Order Preference by Similarity to Ideal Solution (TOPSIS). Prosiding Seminar Nasional Riset Information Science (SENARIS), 1(1), 69. https://doi.org/10.30645/senaris.v1i0.9

Dwijayadi, I. N. A. A., Wirawan, I. M. A., \& Divayana, D. G. H. (2018). Pengembangan Sistem Pendukung Keputusan Penentuan Hotel Di Kecamatan Buleleng Dengan Metode Analytic Hierarchy Process (AHP) Dan Technique for Others Reference By Similarity To Ideal Solution (Topsis). Kumpulan Artikel Mahasiswa Pendidikan Teknik Informatika (KARMAPATI), 7(1), 10. https://doi.org/10.23887/karmapati.v7i1.13590

Herman Firdaus, I., Abdillah, G., Renaldi, F., \& Jenderal Achmad Yani J1, U. (2016). Sistem Pendukung Keputusan Penentuan Karyawan Terbaik Menggunakan Metode Ahp Dan Topsis. Seminar Nasional Teknologi Informasi Dan Komunikasi, 2016(Sentika), 2089-9815.

Kaesmetan, Y. R., \& Nawa, Y. L. (2017). Pemilihan Hotel Pada Kelurahan Oesapa Selatan Menggunakan Metode Weighted Product. 2430 .

Lund, A. M. (2001). Measuring usability with the USE questionnaire. Usability Interface, 8(2), 36.

Maryuliana, Subroto, I. M. I., \& Haviana, S. F. C. (2016). Sistem Informasi Angket Pengukuran Skala Kebutuhan Materi Pembelajaran Tambahan Sebagai Pendukung Pengambilan Keputusan Di Sekolah Menengah Atas Menggunakan Skala Likert. Jurnal Transistor Elektro Dan Informatika, 1(2), 1-12.

Munthafa, A., \& Mubarok, H. (2017). Penerapan Metode Analytical Hierarchy Process Dalam Sistem Pendukung Keputusan Penentuan Mahasiswa Berprestasi. Jurnal Siliwangi, 3(2), 192-201.

Wahyuni, E. G., \& Anggoro, A. T. (2017). Sistem Pendukung Keputusan Penerimaan Pegawai dengan Metode TOPSIS. Sains Teknologi Dan Industri, 14(2), 108-116. 